\title{
PERE MARSILI Y EL ISLAM
}

Antoni Biosca Bas

Universitat d'Alacant

antoni.biosca@ua.es

\section{Resumen}

La obra del dominico mallorquín Pere Marsili, del siglo XIV, no ha sido aún estudiada en todos sus aspectos. Sus dos obras conocidas son la crónica de Jaume I y la Carta a Abdalá. El primer texto es una traducción latina del texto catalán del Llibre dels fets que Marsili adaptó con la intención de resaltar la figura de Jaume I, según le encargó el rey Jaume II. La Carta a Abdalá es una obra epistolar en la que critica la conversión al islam de un franciscano mallorquín. Ambas obras muestran que Marsili incluyó la lucha intelectual contra el islam entre sus objetivos. Estas características hacen que Marsili deba ser tenido en cuenta en la historia de la literatura antiislámica, sobre todo porque participa de la política seguida por la Corona de Aragón durante el siglo XIv, favorable a los dominicos.

\section{Palabras clave}

Pere Marsili, Llibre dels fets, Jaume I, Jaume II, Abdalá, Dominicos, Franciscanos, Islam, Conversión religiosa, Disputa religiosa.

\begin{abstract}
The work of Pere Marsili, a Majorcan Dominican of the fourteenth century, has not yet been studied in all its aspects. His known works are the chronicle of James I and the Letter to Abdullah. The first text is a Latin translation of the Catalan Llibre dels fets that Marsili adapted intending to highlight the figure of James I, following the instructions of King James II. The Letter to Abdullah is an epistolary work in which Marsili criticizes the conversion to Islam of a Majorcan Franciscan. Both works show that Marsili included the intellectual struggle against Islam in his aims. These features show that Marsili should be taken into account in the history of anti-Islamic literature, especially as a part of the policy followed by the Crown of Aragon during I4th century, favorable to the Dominicans.
\end{abstract}




\section{Keywords}

Pere Marsili, Book of Deeds, James I, James II, Abdullah, Dominicans, Franciscans, Islam, Religious Conversion, Religious Disputation.

El papel jugado por la Corona de Aragón a lo largo del siglo XIII en los conflictos bélicos con los reinos musulmanes meridionales es bien conocido en el ámbito popular. ${ }^{\mathrm{I}}$ No es, quizá, tan conocido su papel en la lucha intelectual y teológica frente a la religión de los estados rivales. Este tipo de guerra, en la que la pluma sustituía a la espada, estaba formado por numerosos episodios en los que determinados personajes participaron con sus escritos en esta contienda religiosa. Uno de los escenarios más interesantes de esta lucha es el que se produjo en la Corona de Aragón a lo largo de los siglos XIII y xiv, cuando la corona apoyó claramente la lucha intelectual de los dominicos contra los musulmanes, lucha que tomó forma de tratados y refutaciones que pretendían mostrar la inferioridad teológica del islam frente al cristianismo. ${ }^{2}$ Esta jugada intelectual, que forma parte de la larga lucha antiislámica, debe entenderse en el contexto de una época en la que ciertos ambientes eclesiásticos aspiraban a la conversión masiva de los musulmanes al cristianismo. La estrategia propuesta por los dominicos pretendía, de alguna manera, superar el fracaso que habían sufrido los franciscanos - fracaso en este sentido, es decir, la derrota general del islam- en su pretensión de conseguir conversiones masivas a través de misiones llevadas hasta tierras islámicas. El propio san Francisco había viajado hasta Túnez para intentar convencer personalmente al sultán. ${ }^{3}$ Estas misiones provocaron numerosas escenas de martirio, ${ }^{4}$ hecho que mereció la crítica, ya a principios del siglo XIII, de Thomas de Chobham, quien en su Summa de arte praedicandi, consideraba que la estrategia misionera franciscana se había convertido en un medio de conseguir la salvación personal a través del martirio sin conseguir ningún efecto en la conversión de los musulmanes.

I Este trabajo forma parte del proyecto excelencia I+D "Fuentes medievales y modernas para el estudio de las relaciones transculturales en el Mediterráneo: redacción y transmisión”, dirigido por Cándida Ferrero Hernández de la Universitat Autònoma de Barcelona del Ministerio de Economía y Competitividad (código FFI20I5-63659-C2-I-P MINECO/FEDER).

${ }^{2}$ Para una panorámica de la estrategia dominica frente al islam, véase Tolan (2002, pp. 233255).

${ }^{3}$ Sobre este episodio, véase Tolan (2009).

${ }^{4}$ Algunas de ellas descritas y estudiadas en Ferrero (20II).

5 Descrito por Tolan (2002, pp. 230-23I). Como panorámica de la estrategia misionera de los franciscanos, véase Tolan (2002, pp. 214-232). 
La nueva estrategia dominica partía de esta crítica y establecía frente al islam una nueva estrategia basada en la disputa teológica y la argumentación escolástica. El estado medieval que más confianza puso en la estrategia de los dominicos fue la Corona de Aragón, quien confió ésta en los dominicos catalanes Ramón de Peñafort y Ramón Martí. ${ }^{6}$ En este contexto se debe situar la obra del dominico mallorquín Pere Marsili.

Los principales datos que conocemos de la vida de Marsili se sitúan a principios del siglo XIV. Según narra el historiador Jerónimo Zurita, en I309 realizó una misión diplomática ante el papa representando a Jaume II que resultó un poco accidentada por la insistencia de Marsili, hecho que molestó al papa. ${ }^{7} \mathrm{La}$ documentación conservada indica que en 1313 terminó la versión latina del Llibre dels fets, libro de memorias del rey Jaume I, según le había encargado Jaume II, y que Marsili recibió un pago de los presupuestos de la corona. ${ }^{8}$ El resultado recibió el título de Chronice illustrissimi regis Aragonum domini Iacobi uictorissimi principis, pero se le suele citar con el título breve de Liber gestorum, título que aparece en uno de los manuscritos que lo conservan. Su otra obra conocida, cuya fecha de redacción desconocemos, está formada por una carta literaria destinada a un franciscano mallorquín que se había convertido al islam, y que tituló Littera cuidam apostate Ordinis Fratrum Minorum, prius uocato frater Andreas, postea uero, factus Sarracenus, uocabatur Abdalla. ${ }^{\text {? }}$

En muchas ocasiones los especialistas han hecho referencia al Liber gestorum para tratar la posible anterioridad de la versión latina respecto al Llibre dels fets catalán. Esta propuesta, nacida a principios del siglo XIX, ha tenido un eco desproporcionado y está hoy sobradamente descartada. El manuscrito más antiguo del Liber gestorum conservado, que es además el autógrafo de Marsili, es anterior a los manuscritos conservados del Llibre dels fets, pero no es anterior a la redacción de la obra catalana, de la que procede sin duda el texto latino de Marsili. ${ }^{\text {. }}$

Son muchos los aspectos de la obra de Pere Marsili que aún no han sido tratados en profundidad. La importancia de la crónica latina de Marsili puede

${ }^{6}$ Sobre la autoridad de Martí en este contexto, véase Szpiech (20II y 20I2).

7 Zurita, Anales de la Corona de Aragón, 5, 82. Hemos seguido la edición electrónica de Ángel Canellas López, publicada on-line por la Institución Fernando el Católico en 2003.

${ }^{8}$ Véase Finke (1908, p. 899).

9 Ambas obras están editadas recientemente en la colección Corpus Christianorum, véase Biosca (20I5a). Hay una edición anterior de la crónica en San Pedro (I984), y otra de la epístola, sólo a partir de un manuscrito, en Biosca (2012).

Io Sobre esta cuestión, véase Biosca (2015b), donde, además, se propone un stemma codicum de los manuscritos del Llibre dels fets. 
constatarse por su presencia en los oficios religiosos que celebraban los aniversarios de las conquistas de Jaume I, al menos en Mallorca. ${ }^{\text {II }}$ Otros especialistas han subrayado la importancia de esta crónica como fuente histórica independiente del Llibre dels fets. ${ }^{\mathrm{I} 2}$ Algunas cuestiones del estilo literario de Marsili, que muchas veces ha sido denostado, han merecido la reciente atención de estudiosos como muestra de la calidad literaria de sus obras. ${ }^{\mathrm{I} 3}$ La riqueza e interés del léxico del latín de Marsili, quien realizó una traducción del romance al latín cuando lo habitual era traducir del latín al romance, ha sido estudiada igualmente en los últimos años. ${ }^{14}$ Entre otros aspectos de la obra de Marsili que aún no han sido tratados con detalle está el del papel de su obra en la lucha intelectual contra el islam. Con este trabajo pretendemos dar una aproximación que pueda servir para ayudar a completar este espacio. ${ }^{\text {IS }}$

La crónica de Pere Marsili pretende mostrar una imagen idealizada del rey Jaume I, y por ello, amplia, suprime o altera los pasajes que puedan servir mejor a formar una imagen idealizada del rey conquistador. La obra presenta un interesante prólogo en el que éste explica los motivos que le han llevado a la redacción de la misma. Marsili, lógicamente, no dice nada del pago recibido por escribir la crónica, pero sí se muestra desconcertado ante la brevedad con la que el cronista Rodrigo Jiménez de Rada había descrito la vida de un rey tan importante como era Jaume I, ya que sólo había dedicado una brevísima descripción de sus conquistas en el capítulo quinto del sexto libro de su obra De rebus Hispaniae. ${ }^{16}$ Marsili señala aquí que su obra pretende resarcir esta injusticia y que, de esta manera, se evitará "el pernicioso olvido, madre de la equivocación”. "El prólogo señala igualmente el claro matiz mesiánico de la figura de Jaume I: "Sus hazañas derrotan el poder de los infieles sarracenos en infinidad de lugares, conquistan sus reinos, derrotan sus ciudades, derriban sus castillos y expulsan de sus propias moradas a los enemigos de la cruz de Cristo. Podemos decir con placer $-\mathrm{y}$ aun

II Sobre esta cuestión véase Biosca (20IIa).

${ }^{\mathrm{I}}$ Es especialmente interesante el capítulo dedicado a Marsili en Vinas (2004, pp. 207-227).

${ }^{13}$ Sobre el estilo y la calidad de Marsili, véase Puche (20I2 y 20I4).

${ }^{14}$ Sobre los neologismos en el léxico de Marsili véase Biosca (2013a).

Is Algún aspecto de esta cuestión ya había sido tratada en Biosca (2012 y 2013). Otros aspectos pendientes se explican en Biosca (en prensa).

${ }^{16}$ Fernández (1987, pp. I82-183). El mismo pasaje se lee en la traducción castellana de Fernández (1989, pp. 226-227). Sobre esta cuestión, véase también Mesa (2012). Sobre la trascendencia de la figura del rey Jaume I, véase Belenguer (1984).

${ }^{17}$ Perciniosa obliuio, mater erroris, (Crónica, prólogo 7). Todas las traducciones son nuestras. Actualmente se está elaborando una traducción al castellano de las obras completas de Pere Marsili para la colección Corpus Christianorum in Translation, de la editorial Brepols. 
si no nos gustara decirlo, las pruebas nos obligarían a hacerlo-, que el dedo de Dios está ahora mismo en esta narración, al igual que la mano de Dios estaba en las obras del rey. Y es que nadie podría hacer tantas proezas como las que él hizo, si no es que cuenta con la ayuda de Dios. ${ }^{, 18}$ Según indica Marsili, el carácter mesiánico de Jaume I se vislumbra principalmente en la conquista de los territorios de los musulmanes.

La traducción de Marsili está muy afectada por la búsqueda de una descripción del rey Jaume I que pudiera servir al encargo recibido y, por consiguiente, a los intereses de la corona. Algunos capítulos iniciales señalan el papel de la providencia en cada uno de los detalles de su infancia, añadiendo incluso un capítulo nuevo, ausente en el Llibre dels fets, sobre las señales divinas que rodeaban al rey. ${ }^{\text {19 }}$

El propio método de trabajo a la hora de traducir se ve afectado por la finalidad de la obra. Podrían aducirse muchísimos ejemplos de esta forma de traducir de Marsili, pero daremos aquí sólo una muestra. En una escena de la conquista de Mallorca de I229, el Llibre dels fets da la siguiente información: I nosaltres davallàrem puig avall, $i$ ens ajuntàrem amb la gent de la senyera, i pujàrem allà dalt tots junts. I els sarraïns fugiren. I trobàrem uns dos mil sarraïns que anaven a peu davant nostre, i fugien. ${ }^{20}$ Se trata de un escena de la batalla de Portopí, previa a la conquista de la ciudad de Mallorca. Marsili da la siguiente versión: "Entonces el rey descendió de la montaña y se unió a la muchedumbre, y subieron todos juntos hacia la colina. Y los musulmanes, aterrorizados por un pánico desmesurado, huyeron. Pero los cristianos, ayudados por el Señor, los masacraban, humillaban y destrozaban para que así claramente se contemplara allí el poder de Dios. Huyeron ante ellos unos dos mil soldados de infantería". ${ }^{21}$ Nótese cómo Marsili se

I8 Perfidorum Sarracenorum ubique potestatem debellant, regna acquirunt, ciuitates deuastant, castra deiciunt, et crucis Christi aduersarios de propriis eiciunt laribus. Dicere uolumus, et, si nolentes simus, cogimur, quia digitus Dei est hic, et uere manus Dei erat cum illo. Nemo enim posset hec signa facere que hic fecit, nisi Deus sibi assistat (Crónica, prólogo 4).

${ }^{19}$ Crónica I, 4, capítulo en el que se describen como señales procedentes de la divina providencia los cantos de los monjes cuando el rey entra por primera vez en una iglesia, la elección del nombre del rey o la supervivencia del niño ante la accidental caída de una roca.

${ }^{20}$ Llibre dels fets 65. Seguimos la edición de Bruguera (I99I) por ser la más conocida, aunque actualizamos las grafías para comodidad del lector. Debe destacarse también la edición de FerrandoEscartí (2010), que incluye nuevas lecturas procedentes de otro manuscrito.

${ }^{21}$ Tunc rex descendit de monte, et adiunctus est multitudini, et ascenderunt omnes simul uersus collem. Et Sarraceni, timore mirabili perterriti, fugerunt. Christiani autem, adiuti a Domino, trucidabant, prostrabant, mutilabant, ut uere Dei uirtus ibi manifesta uideretur. Fugerant autem ante eos bene duo milia peditum, et rex non poterat eos consequi (Crónica II 2I, 20). 
ha permitido ańadir una descripción de la ferocidad de las tropas del rey que muestra la superioridad militar de quien tiene el respaldo divino.

Como es esperable en el latín de la época, Marsili traduce sistemáticamente el término catalán moro, tan frecuente en el Llibre dels fets, por el latino Sarracenus. Sin embargo, el término latino se ve acompañado en ocasiones de adjetivos denigrantes, ausentes en el Llibre dels fets, entre los cuales destaca perfidus. El pasaje del prólogo citado más arriba ya muestra una referencia a los perfidi Sarraceni, y son muy numerosos los pasajes en que Marsili traduce el texto catalán ańadiendo de su cosecha el apelativo perfidus. Por ejemplo, en la escena en que el rey le pregunta a la reina avets esguardat què han feit aquests sarraïns, com són entrats alegrament denant nos?, Marsili entiende que la pregunta puede traducirse al latín como attendistis uos, regina, qualiter Sarraceni isti perfidi cum leticia cordis quam celare non poterant aduenerunt?. 22 Nótese que aquests sarraïns se han convertido en Sarraceni isti perfidi. Casos como éste se dan con frecuencia a lo largo de toda la crónica.

Uno de los personajes musulmanes que con mayor frecuencia recibe la apelación de perfidus es Al-Azraq, caudillo que intentó crear un pequeño estado islámico que sobreviviera entre las pretensiones expansionistas castellanas y aragonesas. ${ }^{23}$ Siempre que en el Llibre dels fets se hace referencia a este personaje, aunque no haya ningún apelativo, Marsili añade el adjetivo perfidus. ${ }^{24}$ El empleo de este adjetivo es tan constante que incluso se añade en un contexto forzado, como es la escena en que el rey decide firmar un pacto con él, de manera que cuando el rey narra en primera persona nos donam a Alaçrach treuga, Marsili entiende que lo hizo postulans treugas dari per eum perfido Alazrac. ${ }^{25}$

La inclusión del apelativo perfidus como apelativo denigratorio general de los musulmanes afecta al propio Mahoma. En la escena en que Jaume I pretende convencer a las cortes catalanas de que ayuden económicamente la expedición de socorro que quiere enviar en ayuda de Castilla, el rey les dice: Què hi guanyarets vosaltres, si en les esglésies on és honrat nostre Senyor e la sua Mare que, si per mala ventura se perdia, seria-hi honrat Mahomet? Marsili traduce el pasaje de la siguien-

${ }^{22}$ Llibre dels fets 362 y Crónica III, 63, 8, respectivamente.

${ }^{23}$ Sobre este personaje, véase Garrido (2016).

${ }^{24}$ Sirvan de ejemplos, entre otros: Car hon més se apoderaria Alazrch, pejor seria de cobrar (Llibre dels fets 36I), Nam quanto plura et maiora loca Alazrac perfidus occuparet, tanto fieret potentior et ualidius defenderet occupata (Crónica III 63, 5);o E aquels que romaseren en la nostra terra faeren cap d'Alaçrach (Llibre dels fets 370), Sarraceni qui in regno Valentie remanserunt preceptum regis de exitu contemnentes coniuncti sunt unanimiter illi perfido Alazrac (Crónica III 67, I).

${ }^{25}$ Llibre dels fets 372 y Crónica III 68, I, respectivamente. 
te manera: Quid honoris si in ecclesiis quibus Christus nunc colitur et adoratur, et eius semper Virgo genitrix (...) regna perdantur et Machometus perfidus reducatur? $?^{26}$ Nuevamente Mahomet se ha convertido en Machometus perfidus.

La identificación del perfidus con la figura del musulmán en la obra de Marsili es absoluta, dada su condición de "infieles" desde el punto de vista cristiano. ${ }^{27}$ En algunos casos el adjetivo llega a sustituir plenamente a Sarracenus, de manera que se entiende que los perfidi, sin más explicaciones, son los musulmanes. Así ocurre al describir un intento de rebelión de los musulmanes: E los moros de la terra, oït açò que era vengut als cristians, e per l'esforç e per lo consell dels janets, pensaren de combatre alguns castells. El pasaje es traducido a su vez por Marsili de la siguiente manera: Diuulgata est horum Christianorum perditio per regnum Valencie et fortificata est intentio perfidorum. ${ }^{28}$ Nótese que la tentativa de los moros de la terra se ha convertido en una simple intentio perfidorum. En realidad, la asimilación de perfidus y el musulmán no es en absoluto original de Pere Marsili. El propio Jaume I, por ejemplo, ya había asimilado el adjetivo latino a los musulmanes. En un documento de I247 referido precisamente a los símbolos religiosos de los nuevos reinos, el rey describe a los musulmanes de Mallorca y Valencia como perfidi pagani, y, más adelante, describe sus costumbres como mores perfidorum. ${ }^{29}$

Hay otros ejemplos de cómo Pere Marsili adornó la información que traducía del Llibre dels fets con referencias desfavorables al islam. Un caso significativo es el epíteto pseudopropheta que acompaña al nombre de Mahoma. Si en el LdF és cridat e invocat lo nom de Mahomet, en la crónica de Marsili inuocatur et colitur nomen illius pseudoprophete Machometi: Mahoma o Mahomet, que ya se había des-

${ }^{26}$ Llibre dels fets 384 y Crónica III 7I, 2, respectivamente.

${ }^{27}$ La crónica de Marsili emplea también este apelativo para referirse a los tártaros (IV 2O, I) o los judíos (IV 25, 5).

${ }^{28}$ Llibre dels fets 556 y Crónica IV 54, 2, respectivamente.

29 Documento del 5 de mayo de I247, publicado por Huici (1976, pp. 258-260). Noverint universi quod nos Iacobus, Dei gracia rex Aragonum... ad honorem illius, per quem reges regnant et principes loquuntur iusticiam, devictis iam per nos divino auxilio in finibiis Hispanie barbaricis nacionibus, cupientes civitates et regna Valencie et Maioricarum, que dudum a perfidis captivata paganis, dignata est divina clemencia nostro ministerio restituere cultui Christiano, in statum debitum, iuxta Christianum morem, in melius reformare, ut abiectis vetustatibus et moribus perfidorum, quodam nove generacionis augmento usus Christiane religionis longos ponat ubique funiculos et sua possit tentoria dilatare, subditorum utilitatibus deliberato consilio providentes, monetam cudi fecimus sub signo salutifere crucis supra florem et nomen regni Valencie posite, nostre eciam imaginis et nominis insignis figuratam, ut sit Christianis omnibus, Iudeis et Sarracenis in supradictis civitatibus et regnis comorantibus, necnon et aliis omnibus undecunque ibidem confluentibus una et comunis forma monete, qua sola in suis comerciis, empcionibus et vendicionibus et quibuscunque aliis paccionibus et contractibus absque trepidacione utantur. 
crito antes como perfidus, se ha convertido en ille pseudopropheta Machometus. ${ }^{30}$ Del mismo modo, cuando se describe la conversión de la mezquita de Murcia en iglesia, Jaume I señala su voluntad de que el tempo esté dedicado a la Virgen: volguem honrar lo nom de la Mare de Déu, que hi fos ella honrada per tots temps. ${ }^{3 \mathrm{~T}}$ Marsili, por su parte, se permite añadir cierta información en la que el término pseudopropheta hace clara referencia a Mahoma, aun sin citarlo: mandanit in dicta mezquita maiori edificari altare, ut domus que tot annis illi pseudoprophete seruierat erroneo cultui, iam facta mutatione per dextram Excelsi, beatissime matri et uirgini perpetuis temporibus deseruiret. ${ }^{32}$ El término pseudopropheta, presente en los tratados antiislámicos ya desde el siglo ix para referirse a Mahoma, procede, en última instancia, de la advertencia del mismo Jesús contra los falsos profetas, atribución que los tratadistas medievales no dudan en identificar con Mahoma: multi pseudoprophetae surgent, et seducent multos. ${ }^{33}$

Hay, quizá, dos escenas de la crónica de Marsili que merecen una atención especial desde el punto de vista del estudio de la imagen del musulmán, ya que se trata de escenas en las que Marsili ha ampliado considerablemente la información aparecida en el Llibre dels fets para crear discursos de personajes. Se trata, en ese sentido, de pasajes en los que Marsili ha sido especialmente libre para redactar el texto, pues se apartaba de la necesidad de seguir un original.

El primero de estos pasajes es el discurso fúnebre sobre la muerte de los Montcada tras la batalla de Portopí, en Mallorca. ${ }^{34}$ En el Llibre dels fets se hace referencia a las lágrimas del rey al enterarse de la muerte de los Montcada, lágrimas necesariamente breves por la necesidad de actuar en la batalla, y, un poco más adelante, se mencionan las palabras del rey ante el entierro de los caídos en la batalla en general. ${ }^{35}$ Esta información es recogida por Marsili para crear un discurso fúnebre sobre los Montcada que no debe ponerse en boca del rey, sino en la suya propia, como una digresión propia del autor. ${ }^{36}$ Los Montcada son descritos aquí

${ }^{30}$ Llibre dels fets 362 y Crónica III 63, 4, respectivamente.

${ }^{31}$ Llibre dels fets 450.

${ }^{32}$ Crónica IV I2, I.

${ }^{33}$ Mateo 24, II.

${ }^{34}$ Crónica II 22. Sobre este discurso, véase Puche (2015).

${ }^{35}$ En el Llibre dels fets 66 se da la noticia de la muerte de los Montcada, y en el capítulo 68 del mismo se incluye el breve discurso del rey.

${ }^{36}$ Marsili incluye en su crónica varias digresiones, entre las que se pueden quizá destacar la referencia a las señales divinas de la infancia del rey (I 4), la descripción de Mallorca (II I), la descripción de Ramón de Peñafort (IV 47-49) o la descripción del puerto de Salou (II I4), entre otras. Sobre este discurso ver también Vinas (2004, pp. 220-22I). 
como pugiles y precones ("guerreros y anunciadores”) de la piedad divina, así como mártires que con su muerte han allanado el camino de sus tropas. Pese a que el objetivo del discurso es el ensalzamiento de los Montcada, hay algunas referencias a los musulmanes que resultan especialmente interesantes. Los musulmanes son llamados miseri Sarraceni, y se les insulta llamándolos "perros": nescitis, canes, quia uerum est quod geritur, et aliud per gesta signatur?" Otra referencia interesante del discurso es la acusación sobre los musulmanes de haber cercenado la cabeza de uno de los Montcada para ponerla en la punta de una lanza: Quid, miseri Sarraceni, facitis, dum abscisum caput super uexillum ponitis: $?^{38}$ La imagen de la cabeza de los Montcada sobre una lanza debió de tener su valor iconográfico, ya que en uno de los manuscritos de la crónica de Marsili puede observarse esta imagen en uno de los márgenes junto al discurso fúnebre. ${ }^{39}$ El Llibre dels fets no dice nada sobre este asunto. Es probable que Marsili haya deducido esta información a partir de un dato aparecido justo antes, cuando en el Llibre dels fets se señala que las tropas islámicas llevaban una bandera blanca y roja con una cabeza en la punta, sin que el rey sepa si la cabeza es humana o de madera: E sus alt en la serra on estaven los sarraïns estava gran companya d'homens de peu, e havia-hi una senyera de vermell e de blanc per lonc meitadada, e una testa d'home o de fust al ferre. ${ }^{40}$ El propio Marsili, quizá contradictoriamente por aceptar la duda de si la cabeza era humana o de madera, había traducido este pasaje y lo había incluido en su crónica: et erat ibi uexillum de rubro et albo per medium distinctis, et in ferro haste habebat caput hominis, siue ligneum siue uerum. ${ }^{4 \mathrm{I}}$ También es posible que este detalle ignominioso para los Montcada fuera ocultado por el ambiente de Jaume I, como se ha sugerido. ${ }^{42}$

El segundo pasaje interesante es el discurso del rey de Mallorca antes de la batalla final. El Llibre dels fets hace referencia a un breve discurso del rey musulmán, pero Marsili convierte esta información en un largo discurso precedido de una detallada descripción del escenario del mismo. ${ }^{43}$ La escena, descrita con maestría por Marsili, representa el temor y la desesperación de los sitiados, a quienes el rey

${ }^{37}$ Crónica II 22, 4 .

${ }^{38}$ Crónica II 22, 4 .

39 Manuscrito 3416 del Archivo Capitular de Mallorca, folio zor de la parte catalana. Para una descripción de este manuscrito, véase Biosca (20I5a, pp. xx-xxi)

${ }^{40}$ Llibre dels fets 64.

${ }^{41}$ Crónica II 2I, I6.

${ }^{42}$ Vinas-Pujol (2008, pp. 79).

${ }^{43}$ Crónica II, 3I. Sobre esta escena, ver Vinas (2004, pp. 220-22I), que se acompaña de una traducción francesa. 
quiere alentar antes de la batalla para animarlos a la lucha. El monarca mallorquín es descrito en una breve cadencia positiva en este caso, como alguien ingenio acutus, habitu nitidus, sermone placidus, y sentenciis prouidus ("de ingenio agudo, pulcro de ropas, de discurso agradable y rico en juicios") que es esperado por la muchedumbre y entra en silencio en la escena. Antes de comenzar su discurso pronuncia una breve oración: Rex, eos aspiciens, uulneratus in mente, aperuit os suum, et pro directione sermonis inuocauit Deum, et uoce dulcius prolata aduocatum interseruit Mahometum ("el rey, mirándolos, herido en sus pensamientos, abrió su boca y, para encaminar su discurso, invocó a Dios y, con voz dirigida más suavemente, se refirió a Mahoma”). Es muy probable en esta descripción de la oración Marsili se refiera a la basmala, es decir, la breve oración islámica que da inicio a cualquier acto importante, y a la shahada, que hace referencia a Mahoma como enviado de Dios. ${ }^{44}$ Sobre estas oraciones, Marsili señala la sorprendente uniformidad de los musulmanes al arrodillarse a la vez, como si se tratara de un solo hombre, para tocar el suelo con la frente: statim tota illa multitudo quasi uir unus more solito genua flexit, et, datis terre frontibus, utrasque manus expandit, et inmenso clamore Dominum inuocauit ("de repente, toda aquella muchedumbre dobló sus rodillas según su costumbre como si fueran un solo hombre, y, tras tocar con sus frentes el suelo, extendió sus brazos e invocó al Señor con un clamor enorme"). ${ }^{45}$ Esta descripción coincide con la del rezo multitudinario en una mezquita, aunque en esta ocasión se refiera al discurso de un rey. Marsili añade un detalle negativo, quizá procedente de prejuicios de la época contra los musulmanes, al señalar que éstos consideran que la fuerza con la que gritan el nombre de Mahoma sirve para liberarles: illud nomen sui prophete cum deuotione intensiore pronunciant quasi sint eius meritis liberandi ("pronuncian el nombre de su profeta con mayor devoción, como si fueran a liberarse por mérito de aquél”). ${ }^{46}$ Marsili no duda en considerar aquí al islam una simple superstición herética: peracto sue supersticionis officio, resedit populus ("acabado el ritual de su superstición, se sentó el pueblo"). ${ }^{47}$

El discurso del rey de Mallorca ya ha sido estudiado en otras ocasiones. ${ }^{48}$ Quizá sea interesante destacar aquí el juego retórico que realiza Marsili al poner en

${ }^{44}$ Sobre la basmala en latín, véase Biosca (20Irb).

${ }^{45}$ Crónica II 3I, 2.

${ }^{46}$ Crónica II 3I, 2.

47 Crónica II 3I, 3.

${ }^{48}$ Sobre este discurso véase Vinas (2008, pp. 224-225), que incluye una traducción francesa, y Puche (en prensa). 
boca del musulmán algunos apelativos contra los cristianos, como in thalamo homicida ("asesino en el dormitorio"), uenenum in parapside ("veneno en el plato"), o pacis tempore mors in domo ("muerte en casa en tiempo de paz"). Todos ellos indican un ataque inmerecido y traicionero, como resultaría, a ojos de Marsili, la percepción que tendrían los musulmanes mallorquines de la invasión de Jaume I. Uno de estos apelativos es especialmente interesante, ya que procede de textos cristianos anteriores. Es el caso de ignis in sinu ("fuego en el rincón"), que ya había sido empleado por Walafrido Estrabón en el siglo Ix o por Petrus Cantor en el xir. ${ }^{49}$ Otros autores anteriores ya habían empleado esta expresión para referirse a los huéspedes incómodos y la habían descrito como parte de un refrán popular, cuya forma completa es mus in pera, ignis in sinu, serpens in gremio ("ratón en la bolsa, fuego en el rincón, serpiente en el regazo"). Lo más llamativo es que esta expresión se había utilizado en repetidas ocasiones para referirse a los judíos. Por ejemplo, la bula Etsi Iudaeos del papa Innocencio III (II98-I216) emplea la expresión para referirse a los judíos como un elemento incómodo de la sociedad que siempre debe estar vigilado. ${ }^{5 \circ}$ En ese sentido, es llamativo el juego retórico de Marsili, que consigue que una denominación cristiana antijudía haya servido para crear un apelativo anticristiano en boca de un musulmán.

Este retrato y discurso del rey de Mallorca hace pensar que en el imaginario de Marsili la figura del musulmán era en parte diferente de la que había conocido Jaume I un siglo antes. De alguna manera, pese a que en el Llibre dels fets se describen hechos históricos referidos a musulmanes, la figura del musulmán de la crónica de Marsili es más literaria que real. Otras escenas de la crónica de Marsili apuntan a esta concepción de la figura del musulmán, como es la escena en que una sarracena ofrece sus joyas al soldado invasor para salvar su vida en pleno saqueo de Mallorca. Según Marsili, las mujeres suplicantes dicen a los soldados tua sint hec, da mibi ut uiuam ("quédate con esto, permíteme conservar la vida"), una frase que quizá conserva ecos procedentes de los salmos. ${ }^{\text {SI }}$ No es fácil calibrar el conocimiento real que Marsili tenía del islam. En ese sentido, parece improbable que Marsili supiera árabe, según se deduce de algunos pasajes de su crónica. En el texto de su traducción hay abundantes arabismos, como también los había en el Llibre dels fets, y en algún pasaje demuestra conocer el uso de un término árabe, como rais: dominus loci qui 'arraiz' Arabice dicebatur ("el señor del lugar que suele

${ }^{49}$ Walafrido Estrabón, Glosas a los Hechos de los Apóstoles, capítulo 2, (Migne, II4, col. 430D), y Petrus Cantor, Carta 87 (Migne, 205, col. 208A)

5o Bula publicada en la Patrologia Latina (Migne, 215, col. 694C).

sI Crónica II 35, I. Cf. Salmos II8, I44. 
decirse arraiz en árabe"). ${ }^{52}$ Sin embargo, su explicación errónea de una etimología árabe permite comprobar que sus conocimientos de árabe, si los había, eran muy escasos: que quasi nomine Arabico Euissa, quasi 'ebiza', id est arida, dicitur ("la cual tiene el nombre árabe de Euissa, de ebiza, que significa 'árida' en árabe”). ${ }^{53}$

Junto a la crónica, debe tenerse en cuenta la otra obra de Marsili, que es mucho más interesante respecto al tema aquí tratado, y mucho menos conocida. Se trata de la breve carta escrita a un franciscano mallorquín convertido al islam, cuyo nombre cristiano era Andreas en latín (deducimos que se llamaría Andreu), quien, tras su conversión, pasó a llamarse Abdalá. Esta conversión muestra coincidencias con el conocido caso de Anselm Turmeda, ya que en ambos casos se trata de franciscanos mallorquines que se convirtieron al islam y recibieron el mismo nombre. En este sentido, el caso narrado por Marsili es el de un precursor de Turmeda. El texto de Marsili, titulado Littera cuidam apostate Ordinis Fratrum Minorum, prius uocato frater Andreas, postea uero, factus Sarracenus, uocabatur Abdalla ("Carta a cierto apóstata de la orden de Hermanos Menores, antes llamado hermano Andreu, pero que después de convertirse en sarraceno se llamaba Abdalá"), no ha recibido apenas atención de los estudiosos. ${ }^{54}$ En el contenido de la carta, la conversión del franciscano es descrita como una monstruosidad terrible que merece los mayores desprecios. El islam es descrito como una secta mentirosa y depravada (ficte et praue secte professio), o como una lepra abominable (tam abhominabilis lepre in corpore tuo). Los apelativos contra su conversión son aún peores: escoria humana (omnium peripsima hominum), motivo de rechazo de cristianos, musulmanes y judíos (Christianis aduersarium, Sarracenis suspectum, Iudeis prouerbium), e incluso causa de violencia, infamia o robo (piratarum et predonum socius, pacificorum insultor, rei aliene amator, obedientie contemptor, paupertatis inuasor). Los apelativos denigrantes contra la conversión de fray Andreu son numerosos, y llegan a compararse con el pecado de Sodoma: peccatum tuum, quasi peccatum Sodome. El tono agresivo de la carta permitiría crear un considerable listado de términos denigrantes contra el islam y, sobre todo, contra la conversión del franciscano.

Un aspecto interesante de este texto que debe encuadrarse en el papel de Marsili en la historia de la lucha intelectual contra el islam, es el de la referencia al martirio como única posibilidad de salvación de Andreu. Esta opción, que el

52 Crónica III 55, 6.

53 Crónica II I,7.

${ }^{54}$ Sobre este texto, véase Biosca (2012). También hay una breve aproximación en Biosca (2013b). 
propio Marsili ve muy improbable, parece indicar una velada crítica de la estrategia franciscana contra el islam, basada, sobre todo, en el testimonio de la fe en tierras islámicas y la asunción del martirio como posible final. La orden dominica, como hemos señalado al inicio de este trabajo, fue crítica con la estrategia franciscana, y estableció frente al islam su propia estrategia basada en la disputa teológica y la argumentación. Esta nueva estrategia, como ya hemos seńalado al principio de ese trabajo, fue especialmente apoyada por la Corona de Aragón gracias a dominicos como Ramón Martí o Ramón de Penyafort." Por ello, que un dominico como Pere Marsili, bien relacionado con la monarquía aragonesa, cierre el texto de la epístola con una referencia al improbable martirio de fray Andreu es un dato en absoluto inocente que, en nuestra opinión, evoca el grave peligro de la estrategia misionera franciscana, ya que puede provocar la perdición de los misioneros más débiles y la nula eficacia de un martirio que no consigue convertir a los musulmanes.

Acercándonos ya a las conclusiones, debemos señalar que el trabajo intelectual de Marsili debe entenderse como parte de la lucha contra el islam forjada en la Corona de Aragón en el siglo xiv en el marco de la larga historia de la literatura contra el islam. Marsili redactó una crónica latina a partir del Llibre dels fets que serviría para ensalzar la figura da Jaume I como rey cruzado vencedor de los musulmanes y conquistador de sus tierras. En esta crónica se permitió añadir información que permitía profundizar en el carácter guerrero del rey frente a los musulmanes, así como teñir a éstos mismos de unas características aún más negativas que las que ya aparecían en la obra catalana. Junto a su crónica, Marsili redactó una carta en la que se describe al islam como a una monstruosidad, y veladamente se acusó a los franciscanos de falta de eficacia en su lucha contra el islam. ¿Cuál fue el resultado de este aspecto de su trabajo? En realidad, la trascendencia de la obra de Marsili, vista con perspectiva actual, es más bien modesta. Su crónica fue empleada en Mallorca como fuente para la preparación del Sermó de la Conquesta, sermón conmemorativo de la conquista de la ciudad celebrado durante la Festa de l'Estendard que celebraba el mismo hecho histórico. ${ }^{56}$ Las anotaciones iniciales del manuscrito autógrafo de Marsili señalan la petición del autor de que el rey Jaume II ordenara que se hiciera una copia del texto y se enviara al

"Para la estrategia de los dominicos ante el islam, véase Tolan (2002, pp. 233-255). Resulta muy significativo que Marsili incluyera la descripción de dominicos como Ramón de Peñafort (Crónica IV 48-50) o Ramón Martí (Crónica IV 25, 5), pero, aun siendo mallorquín, no diga palabra alguna sobre el franciscano Ramón Llull.

${ }^{56}$ Sobre la Festa de l'Estendard de Mallorca, véase Alomar (1998). 
convento de dominicos de Mallorca para conmemorar la conquista. Esta misma anotación informa de la aprobación del rey y el envío de la copia. El manuscrito enviado a Mallorca no se conserva, pero sí dos copias del mismo, cuya colación demuestra que son copias de una versión anterior perdida. ${ }^{57}$ Ambos manuscritos conservan únicamente el libro segundo de la crónica, esto es, la parte dedicada a la conquista de Mallorca. Las anotaciones marginales sobre uno de estos manuscritos informan honoríficamente de los autores del Sermó de la Conquesta a lo largo de los ańos, dato que demuestra que el manuscrito en cuestión sirvió de fuente para la preparación de este sermón. ${ }^{58}$ Las anotaciones, de manos diferentes, sólo abarcan los años I505-I634, pero es probable que el manuscrito anterior, hoy perdido, contuviera las anotaciones de los años anteriores con la misma intención honorífica. Curiosamente, los dos manuscritos conservados de Mallorca contienen también una traducción al catalán del texto de Marsili, probablemente para que pudieran ayudarse de la misma los autores del sermón menos duchos con el latín. ${ }^{59}$ Es posible que los sermones conmemorativos de otras conquistas del rey Jaume I y sus victorias sobre los musulmanes tomaran como fuente la crónica de Marsili, pero a día de hoy no se ha podido demostrar. ${ }^{60}$ Se ha conjeturado que la crónica de Marsili pudo servir para conseguir la canonización de Jaume I como modelo de rey cruzado. ${ }^{61}$ En ese sentido, es conocido que hubo un intento por parte de diferentes monarquías occidentales de conseguir contar entre sus antepasados con la canonización de un rey belicista contra los musulmanes, especialmente Castilla, Aragón y Francia. La canonización de Luis IX de Francia en I297 había mostrado el apoyo del papado hacia la lucha contra los musulmanes en Palestina, apoyo que no llegaría en este aspecto a las monarquías hispánicas, centradas en la lucha contra los musulmanes andalusíes. Castilla consiguió la canonización de Fernando III de forma mucho más tardía, en I67I, en un contexto ya muy diferente, y la Corona de Aragón no llegaría a conseguirlo. La obra de

${ }^{57}$ Los manuscritos conservados en Mallorca, ambos del siglo XIV, son dos: manuscrito 34I6 del Archivo Capitular de Palma de Mallorca, y manuscrito 40 del Archivo del Reino de Mallorca. Para la descripción de los manuscritos y la reconstrucción del subarquetipo, véase Biosca (2015a, pp. XIX-XXIV).

${ }^{58}$ Sobre estas anotaciones, véase Biosca (2011a).

${ }^{59}$ El texto catalán, junto con una traducción castellana, fue traducido por Josep Maria Quadrado (I850).

${ }_{60}^{6}$ Quizá fuera también la fuente del sermón valenciano del 9 de octubre, también referido a la conquista de la ciudad, como indicaba su nombre popular, sermó de les espasades, pero a día de hoy es difícil confirmarlo.

${ }^{61}$ Sobre esta posibilidad, véase Mesa (20I2). 
Marsili ha formado parte de esta lucha por el reconocimiento de Jaume I como rey cruzado merecedor de la canonización. ${ }^{62}$

En 1356 el rey Pedro IV el Ceremonioso consiguió que un dominico mallorquín, Nicolau Rossell, accediera al título de cardenal. Al tratarse del primer cardenal procedente de la Corona de Aragón, fue conocido en Italia con el sobrenombre de "el cardenal de Aragón". Rossell, compañero de origen y de orden de Marsili, se mantuvo siempre en la corte papal, con la intención de defender los intereses de su estado y de la corona que lo había promocionado. Los once manuscritos conservados de la Epistola a Abdalá, aunque son posteriores al siglo XIV, están relacionados con la obra de Rossell y comparten sus códices con los escritos del cardenal. ${ }^{63}$ Es fácil deducir que Nicolau Rossell había tenido un especial interés en conservar la obra de Marsili como apoyo en sus actuaciones políticas ante el papa, fueran las que fueran, y había conservado sus textos como parte de su documentación. Esto demuestra que en la lucha política y propagandística de la Corona de Aragón ante el papado, la obra de Pere Marsili tuvo una relevancia especial, al menos, durante el siglo XIV. Por todo ello, no debería subestimarse la importancia de la obra de Pere Marsili como parte de la historia de la literatura polemista antiislámica.

\section{OBRAS CITADAS}

Alomar Canyelles, A., 1998: L'Estendard, la festa nacional més antiga d'Europa (s. XIII-XXI), Palma.

Belenguer Cebrià, E. 1984: Jaume I a través de la història, Valencia.

Biosca Bas, A., 2005: "Una nueva aportación a los nombres de los musulmanes en latín medieval", Euphrosyne, 33, pp. 315-322.

Biosca Bas, A., 20ria: "Las anotaciones del Sermó de la Conquesta en el MS. 40 del Arxiu del regne de Mallorca", Miscelánea Medieval Murciana, 35, pp. 5I-66.

Biosca Bas, A., 20Irb: "La basmala latine", in Courcelles-Martines (eds.), Pour une histoire comparée des traductions, París.

${ }^{62}$ En I633 el conde de Guimerà intentó revivir el viejo proyecto de canonización de Jaume I, según recuerda Tourtoulon (1874, pp. 414-415). Para la imagen del rey en la posteridad, véase Belenguer (2009) y Escartí (2009 y 20I2). El recuerdo de Jaume I llegó a merecer la creación en el siglo xviII de un largo poema épico en latín, obra del valenciano Josep Ignasi Barberà (Biosca, 2013c).

${ }^{63}$ Para la descripción de los manuscritos y de la relación entre ellos, véase Biosca (2015a, XXVI-XXXVIII). 
Biosca Bas, A., 20I2: "La carta contra el converso mallorquín Abdalá: una obra inédita de Pere Marsili”, Frate Francesco, rivista de cultura francescana, 78/2, pp. 384-399.

Biosca Bas, A., 2013a: "Neologismos de origen catalán en el latín de Pere Marsili", Archivum Latinitatis Medii Aevi, 7I, pp. I27-I38.

Biosca Bas, A., 20I3b: "Pere Marsili", in Thomas - Mallett (eds.), Christian-Muslim Relations. A Bibliographical History. Volume 5 (I350-I500), Leiden, pp. 712-7I4.

Biosca Bas, A., 2013c: "Ėpica Llatina per a Jaume I: el Poema Triumphus Valentinus del novator valencià Josep Ignasi Barberà", Caplletra, 55, pp. 27-47.

Biosca Bas, A., 20I5a: Petri Marsili Opera omnia, Turnhout.

Biosca Bas, A., 20I5b: "La versión latina de Pere Marsili frente a los manuscritos del Llibre dels fets : propuesta de stemma codicum y reconstrucción del arquetipo", Revue d'Histoire des Textes, IO, pp. I03-I40.

Biosca Bas, A., en prensa: "Interès de la crònica llatina de Pere Marsili", Estudis Romànics.

Bruguera, J., I99I: Llibre dels fets del rei en Jaume, vol. I, Barcelona.

Escartí, V. J., 2009: "Jaume I en la historiografia valenciana, de l'Edat Mitjana al Barroc", L'Espill, 32, pp. I7I-I84.

Escartí, V. J., 20I2: "Jaume I, el Llibre dels feits i l'humanisme: un model "valencià" per al cesarisme hispànic», eHumanista/IVITRA I, pp. I28-I40.

Fernández Valverde, 1987: Jiménez de Rada, De rebus Hispaniae, Turnhout.

Fernández Valverde, 1989: Rodrigo Jiménez de Rada. Historia de los hechos de España, Madrid.

Ferrando-Escartí, 20Iо: Llibre dels feits del rei en Jaume, Valencia.

Ferrero Hernández, C. 20II: "Inter Sarracenos. Mártires franciscanos en el Norte de África y en la Península Ibérica (ss. XIII-XVII)”, Frate Francesco, rivista di cultura francescana, 77/2, pp. 26I-277.

Finke, H., 1908: Acta aragonensia. Quellen zur Deutschen, Italienischen, Französischen, Spanischen, zur Kirchen und Kulturgeschichte aus der Diplomatischen Korrespondenz Jaymes II, (I29I I327), Berlín.

Garrido Valls, J. D., 2016: Al-Azraq. El cabdill andalusi que desafià Jaume I, Valencia.

Huici-Cabanes, 1976: Documentos de Jaime I de Aragón, vol. 2, Valencia.

Martínez San Pedro, M. D., 1984: La crónica latina de Jaime I, edición crítica, estudio e indices, Almería.

Mesa Sanz, J., 20I2: "Del Llibre dels Fets a los Gesta Iacobi de Fra Pere Marsili. Historia y Propaganda”, in A. Hauf (ed.), El Llibre dels feits. Aproximació crítica, Valencia. 
Migne, I844-1855: Patrologia Latina, París.

Puche López, C., 20I2: "Dos pasajes de la conquista de Mallorca en la Chronica gestorum Iacobi I de Pere Marsili", Euphrosyne, 40, pp. I9I-207.

Puche López, C., 20I4: "Épica y providencialismo en el Liber gestorum de Pere Marsili”, eHumanista/IVITRA, 5, pp. 406-423.

Puche López, C., 2015: "Creación literaria en Pere Marsili: el planctus por los Montcada en el Liber gestorum”, Filologia Mediolatina, 22, pp. 293-317.

Puche López, C., en prensa: "Discurso e idealización en la crónica de Pere Marsili".

Quadrado, J.M., I850: Historia de la conquista de Mallorca. Crónicas inéditas de Marsilio y Desclot, Mallorca.

Szpiech, R., 20II: "Citas árabes en caracteres hebreos en el Pugio fidei del dominico Ramón Martí: entre la autenticidad y la autoridad”, Al-Qanțara 32/I, pp. 7I-IO7.

Szpiech, R., 2012: "Translation, Transcription, and Transliteratio in the Polemics of Raymond Martini, O.P”, en Ch. D. Wright (ed.), Translating the Middle Ages. Aldershot, pp. I7I-187.

Tolan, J., 2002: Saracens. Islam in the Medieval European Imagination, New York.

Tolan, J., 2009: Saint Francis and the Sultan. The Curious History of a Christian-Muslim Encounter, Oxford.

Tourtoulon, C., I874: Don Jaime I el Conquistador, rey de Aragón, conde de Barcelona, señor de Montpeller: según las crónicas y documentos inéditos, vol. 2, Montpellier.

Vinas, A. y R., 2004: La conquête de Majorque. Textes et documents, Perpignan.

Vinas-Pujol, 2008: El llibre dels fets de Jaume el Conqueridor, Mallorca.

Zurita, J., 2003: Anales de la Corona de Aragón, Á. Canellas López (ed.), edición electrónica de la Institución Fernando el Católico. 